\title{
Update on anaplastic large cell lymphoma in women with breast implants
}

\author{
Walter Peters PhD MD
}

W Peters. Update on anaplastic large cell lymphoma in women with breast implants. Plast Surg 2014;22(4):267-269.

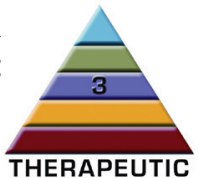

Since 1997, reports from the scientific community have suggested a possible association, without causation, between breast implants and anaplastic large cell lymphoma (ALCL). Analysis of these patients has been challenging. Many studies have been under-reported while others have been duplicated. In 2011, a United States Food \& Drug Administration (FDA) 'white paper' analyzed 34 of the 60 cases reported worldwide. All 34 patients had undergone secondary surgery for breast swelling, firmness or pain. ALCL was an incidental finding. Diagnosis of ALCL is made by hematoxylin and eosin histology and immunochemistry for the CD30 marker. ALCL occurred with all types of implants. Subsequent studies have suggested that textured implants may have a greater risk. In all cases, ALCL cells were found in the capsule, in the seroma or within a mass adjacent to the implant. There was no invasion of cells beyond the capsule into the breast parenchyma. From the FDA study, the risk of developing ALCL after receiving implants appears to be approximately one in one million per year. All cases appear to be negative for the anaplastic lymphoma kinase marker. ALCL in most of these patients may represent a new entity with less aggressive behaviour. In most patients with capsule-confined disease, proper management may prove to be implant removal and capsulectomy. Patients with a distinct mass adjacent to their implant may have a more aggressive clinical course that may become systemic. They may require chemotherapy in addition to implant removal and capsulectomy. All cases of ALCL should be referred to an appropriate specialist and reported to the FDA.

Key Words: ALCL; Anaplastic large cell lymphoma; Breast implant

\section{ANAPLASTIC LARGE CELL LYMPHOMA IN WOMEN WITHOUT IMPLANT EXPOSURE}

Anaplastic large cell lymphoma (ALCL) is a rare type of non-Hodgkin lymphoma involving $\mathrm{T}$ cell lymphocytes, which are stem cells of the immune system (1). There are two types of lymphoma, each with different cell types: Hodgkin lymphoma, which has characteristic Reed-Sternberg cells; and non-Hodgkin lymphoma. Figure 1 is a photomicrograph of homogeneous Hodgkin lymphoma lymphocytes. A diagnostic Reed-Sternberg 'popcorn cell' with a 'moth-eaten' appearance is visible in the left lower field.

In ALCL, the cells are very different from Hodgkin lymphoma cells. The term 'anaplastic' refers to cells that have become highly abnormal. Histology reveals large cells with pleomorphic nuclei, abundant cytoplasm, kidney-shaped nuclei and a paranuclear eosinophilic region (Figure 2). Immunohistochemistry is used to confirm the diagnosis of ALCL. These lymphocytes have disease-specific antigens on their surface that react with purified antibodies. The presence of a specific protein cytokine receptor (CD30) is necessary for a definitive diagnosis. There are two major variants of ALCL: one that expresses an additional cell-surface antigen marker (anaplastic lymphoma kinase $[A L K]$ positive); and a second that does not (ALK negative). Patients with ALK-negative cells appear to have a less aggressive outcome than those with ALK-positive cells.

\section{Une mise à jour sur les lymphomes anaplasiques à grandes cellules chez des femmes ayant des implants mammaires}

Depuis 1997, des comptes rendus de la communauté scientifique laissen croire à des associations non causales entre les implants mammaires et les lymphomes anaplasiques à grandes cellules (LAGC). L'analyse de ces patientes est difficile. De nombreuses études sont sous-déclarées, tandis que d'autres sont dédoublées. En 2011, un « livre blanc » de la Food E̊ Drug Administration (FDA) des États-Unis contenait l'analyse de 34 des 60 cas déclarés dans le monde. Les 34 patientes avaient toutes subi une chirurgie secondaire en raison d'une enflure, d'une fermeté ou d'une douleur de la poitrine. Les LAGC étaient des découvertes fortuites. Le diagnostic de LAGC est posé par une histologie de l'hématoxyline et de l'éosine et par l'immunochimie du marqueur CD30. Les LAGC se produisaient dans tous les types d'implants. Selon des études subséquentes, les implants texturés posent peut-être un risque plus élevé. Dans tous les cas, les cellules des LAGC ont été décelées dans la capsule fibreuse, le sérome ou une masse adjacente à l'implant. L'invasion des cellules ne dépassait pas la capsule fibreuse dans le parenchyme mammaire. D'après l'étude de la FDA, le risque de LAGC après des implants semble s'élever à environ un cas sur un million par année. Tous les cas semblent négatifs au marqueur de la kinase du lymphome anaplasique. Chez la plupart de ces patientes, les LAGC peuvent représenter une nouvelle entité moins agressive. Chez la plupart des patientes pour qui la maladie est confinée à la capsule fibreuse, l'extraction de l'implant et la capsulectomie peuvent représenter une bonne prise en charge. Les patientes présentant une masse distincte adjacente à l'implant peuvent présenter une évolution clinique plus agressive qui peut devenir systémique. Elles peuvent avoir besoin d'une chimiothérapie en plus de l'extraction de l'implant et de la capsulectomie. Tous les cas de LAGC devraient être orientés vers un spécialiste pertinent et déclarés à la FDA.

ALCL can occur in the skin as a primary cutaneous form, which is less aggressive and can be treated successfully with local radiation. Approximately $10 \%$ of the time, primary cutaneous ALCL can spread to the lymph nodes and organs to become systemic. This can be treated with radiation and/or chemotherapy.

ALCL in women without breast implants is very rare. The incidence is approximately one in 500,000 per year (1). The incidence in the breast is even lower, three in 100 million per year (2). In these patients, most lymphocytes are of B cell origin. In contrast, in patients with breast implants, all have been of the $\mathrm{T}$ cell phenotype.

\section{ALCL IN WOMEN WITH BREAST IMPLANTS}

Since 1997, reports from the scientific community have suggested a possible association, without evidence of causation, between breast implants and ALCL (3-7). This form of ALCL is not a cancer of the breast tissue, rather, it is a cancer of $\mathrm{T}$ cell lymphocytes. It has not been demonstrated in breast parenchyma. In January 2011, the United States Food and Drug Administration (FDA) issued a 'white paper' describing the risk of ALCL in women with breast implants (8). This study covered a 13-year period from 1997 to 2010. It found at most 60 (34 definite) cases of ALCL in women with breast implants. This equates to 4.6 cases per year. At least seven million women have received breast implants. Therefore, from this FDA study, the risk of

Division of Plastic Surgery, University of Toronto, Toronto, Ontario

Correspondence: Dr Walter Peters, 600 Sherbourne Street, Suite 802, Toronto, Ontario M4X 1W4.

Telephone 416-926-7790,e-mail walter.peters@utoronto.ca 


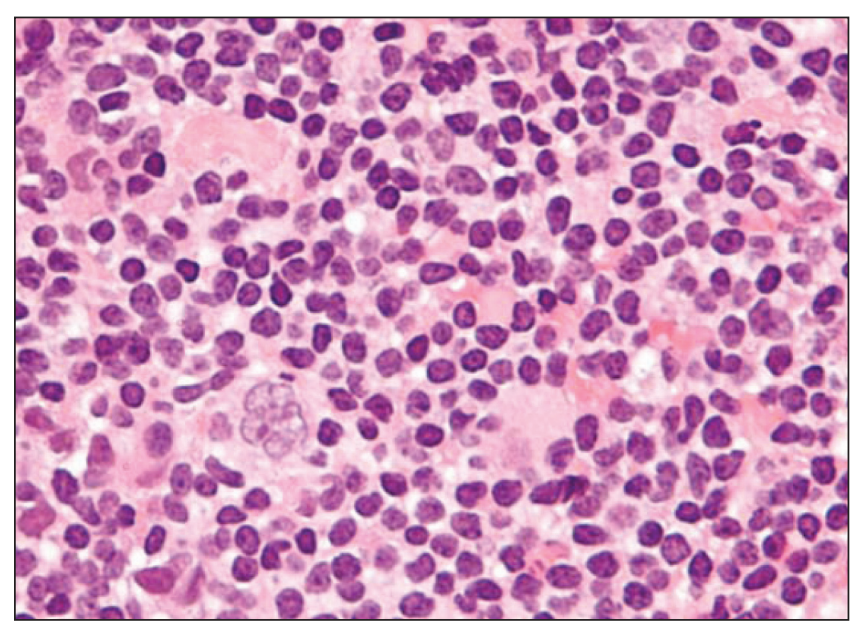

Figure 1) Hematoxylin and eosin stain of a Hodgkin lymphoma showing homogeneous lymphocytes with a diagnostic Reed-Sternberg 'popcorn cell' with a 'motheaten' appearance in the lower left corner of the field (original magnification $\times 200$ ). Adapted from reference 1

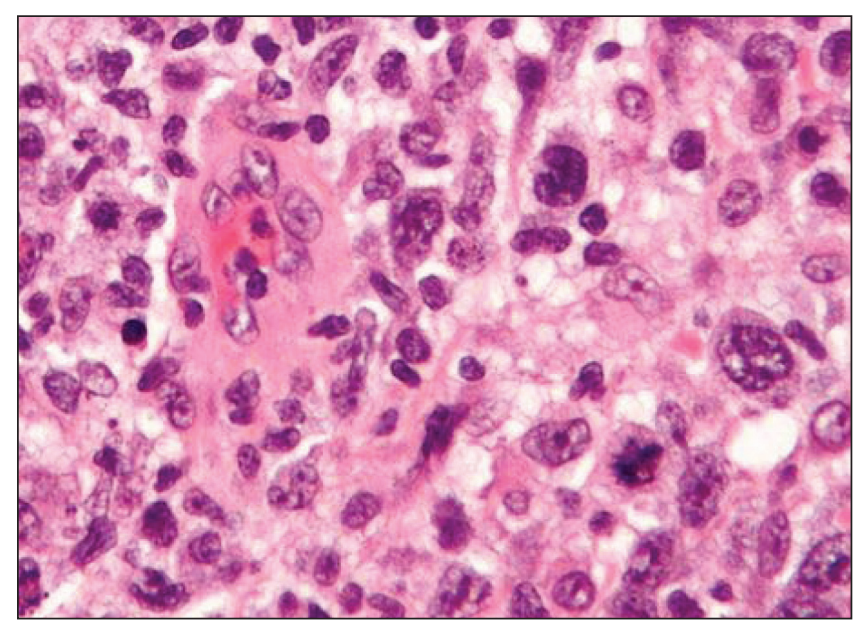

Figure 2) Hematoxylin and eosin stain of an anaplastic large cell lymphoma showing large cells with pleomorphic nuclei, abundant cytoplasm, kidneyshaped nuclei and a paranuclear eosinophilic region (original magnification $\times 200$ ). Adapted from reference 2

developing ALCL in patients with implants appears to be $<1$ in one million per year.

Many scientific groups and regulatory bodies have attempted to analyze these patients. This task has been challenging because many studies have been under-reported and others have been duplicated. Despite these limitations, several observations have been made. The FDA carefully analyzed 34 of the 60 cases of ALCL that were reported globally from January 1997 to 2010. Of the 34 cases, the median time from breast implant placement to ALCL diagnosis was eight years, with a range of one to 23 years. All of these cases occurred in patients who had undergone implant revision surgery to treat capsular contracture, breast swelling or pain. ALCL was usually an incidental finding. Of the 34 patients, ALCL cells were found in the capsules of 21 and in the seroma of 12 . Ten of the 34 patients presented with a 'peri-implant mass', which was positive for ALCL cells. In these patients, the mass was contained within the implant capsule. In every case, there was no invasion of the cells beyond the capsule into the breast parenchyma.

Consistent with ALCL diagnosis, CD30 status was positive in all 29 reports that included this information. Although ALCL in the rest of the body can be either ALK positive or ALK negative, the cases reported in the FDA study were ALK negative in 26 of 34 cases that reported this status. Subsequent reports have confirmed this

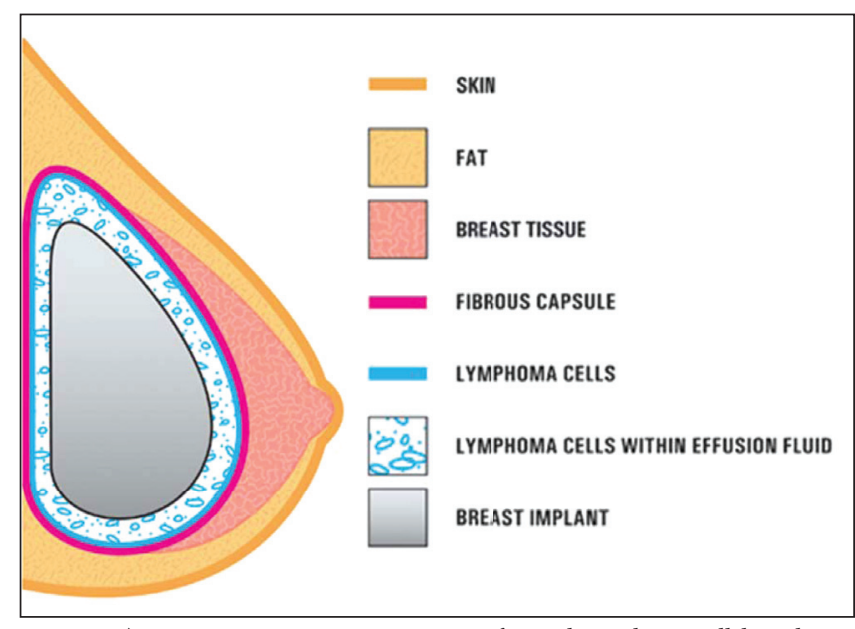

Figure 3) Diagrammatic representation of anaplastic large cell lymphoma cells in the seroma and within the fibrous capsule surrounding a breast implant. Invasion of lymphoma beyond the fibrous capsule into breast parenchyma has not been observed. Adapted from reference 7

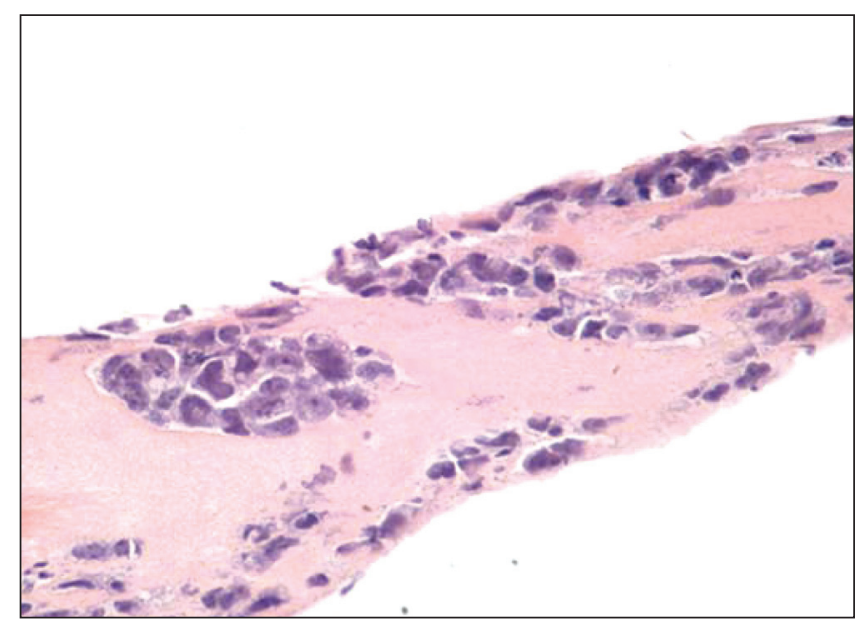

Figure 4) Hematoxylin and eosin stain showing anaplastic large cell lymphoma cells within the capsule around a breast implant (original magnification $\times 200$ ) Adapted from reference 2

ALK-negative status in all cases that have reported an ALK status. Figure 3 presents a diagrammatic representation of ALCL cells in the seroma and capsule surrounding a breast implant (7). Figure 4 shows a hematoxylin and eosin (H\&E) stain of ALCL cells within the capsule surrounding a breast implant (3).

A single case-control Dutch study (8) reported increased chances of association between ALCL and implants. However, there were classification uncertainties in this study. Several patients developed ALCL within one year of receiving implants. This is a short time frame for causation. In addition, three patients may have had secondary lymphomas rather than primary lesions.

ALCL has occurred with silicone gel and saline implants, and with smooth-surfaced and textured implants. Textured implants may have a greater risk. In the FDA study, the nature of the implant surface was not identified in 30 of the 34 patients. In the four patients for whom this information was included, all were textured. In the FDA study, 10 of the 34 patients presented with a seroma that was positive for ALCL cells. Seromas have been shown to be associated with Biocell (Allergan, USA) textured implants $(9,10)$. In the five cases reported from Australia, all implants were textured (6).

In the FDA study, treatment was reported in only 20 of the 60 cases of ALCL; most had their implants removed. Some progressed to receive 
treatment with radiation and/or chemotherapy. Overall, the outcomes were more favourable than would be expected for systemic ALCL. Some researchers have suggested that this form of ALCL may represent a new entity with less aggressive (indolent) behaviour $(4,5)$. This may be similar to the less aggressive primary cutaneous form of ALKnegative ALCL, rather than the more aggressive systemic form.

In their December 2013 publication, Miranda et al (11) extended the clinical follow-up of the FDA study to December 2012, by contacting the corresponding authors of all of these studies. Therapeutic data were available for 55 of the 60 patients: 30 (78\%) received systemic chemotherapy, four $(7 \%)$ received radiation alone and $12(22 \%)$ received no further treatment. Thirty-nine (93\%) of the 42 patients with disease confined to the fibrous capsule achieved complete remission, compared with complete remission in $13(72 \%)$ of 18 patients with a mass adjacent to the implant. These authors concluded that proper management of patients with disease confined within the fibrous capsule may be limited to capsulectomy and implant removal. Patients with a tumour mass have a more aggressive clinical course that may be fatal, justifying cytotoxic chemotherapy in addition to removal of implants and capsules.

Although ALCL is very rare, the FDA believes that women with breast implants may have a very small, but increased, risk of developing ALCL in the fibrous capsule around a breast implant. The risk of developing ALCL in the breasts of women without implant exposure is approximately three in 100 million per year. The risk in the implant patients in the FDA study was approximately one in one million per year.

Although the number of cases of ALCL is small, the actual number may be under-reported. Large numbers of patients have presented to plastic surgeons over the years with capsular contracture, breast swelling and pain. Many of these patients would not have undergone cytological studies because they were not indicated.

Currently, 83 cases of ALCL have been reported worldwide, 82 of which were ALK negative. The median age of diagnosis was 50 years (range 28 to 87 years). The median time from implant placement to diagnosis of ALCL was nine years (range one to 31 years). Implant surface was documented in only 26 of the 83 cases; 24 of these 26 had textured surfaces. A Scientific Advisory Panel on Breast Implantrelated ALCL has been convened by the RAND Corporation in Arlington, Virginia (USA). Twelve panelists have been selected from a number of disciplines. The purpose of this panel is to advance the exchange of medical information related to this very rare condition.

\section{ROLE OF THE PLASTIC SURGEON}

Plastic surgeons should reassure their female patients that the risk of developing ALCL after receiving breast implants is exceedingly small. The calculated risk from the FDA study was approximately one in one million per year. This risk may be slightly higher than in women without breast implants (three in 100 million per year), but this has not been proven. Although this risk is exceedingly low, plastic surgeons should consider the possibility of ALCL in patients presenting with persistent breast swelling, firmness, pain or capsular contracture, which are common symptoms in patients undergoing secondary implant surgery.

When this type of secondary surgery is performed, there is currently no defined 'standard of care' for investigating these patients. However, it may be reasonable to follow a certain practice. In the 34 documented cases of ALCL in the FDA study, 21 had capsular involvement with ALCL cells, 12 had cells in the serous fluid and 10 had cells in a peri-implant mass. Therefore, capsule specimens and any peri-implant mass in suspected cases should be placed in formalin and sent to the laboratory for regular histopathology with H\&E staining and immunochemistry testing. Detection using the ALK-1 and CD30 antibodies is challenging. They require formalin-fixed tissue for optimal assessment. The usual cytology kits use alcohol fixation, which can interfere with immunochemistry analysis. These kits are not necessary to assess ALCL.

If seroma fluid is found during secondary surgery, it can be sent for analysis. The fluid should be placed in a standard formalin specimen bottle. This specimen should be marked 'seroma fluid' to alert the pathologist. When this specimen is sent to the laboratory, it is centrifuged and the sediment is embedded in paraffin to create a 'cell block', which is simply a microbiopsy embedded in paraffin. Sections are then cut and stained with H\&E. Immunochemistry testing is also performed on this 'cell block' to assess for CD30 and ALK-1 markers.

Proper management for patients with disease confined within the fibrous capsule may prove to be limited to capsulectomy and implant removal. Current evidence appears to indicate that adjuvant radiation of chemotherapy may not be necessary for women with capsuleconfined disease. However, these patients should always be referred to an appropriate specialist for evaluation and assessment. Patients with a distinct peri-implant mass have a more aggressive clinical course, which may become systemic. This may justify the use of chemotherapy in addition to removal of the implants and capsules. Any positive cases should be reported to the FDA and to the American Society of Plastic Surgeons, who are working together to create a registry of these patients.

DISCLOSURE: The author has no financial disclosures or conflicts of interest to declare.

\section{REFERENCES}

1. Anaplastic large cell lymphoma, Lymphoma Research Foundation. <www.lymphoma.org/site> (Accessed June 2014).

2. Anaplastic large-cell lymphoma. <www.nlm.nih.gov/cgi/ mesh/2014> (Accessed June 2014).

3. Jewell M, Sear SL, Largent, J, et al. Anaplastic large T-cell lymphoma and breast implants: A review of the literature. Plast Reconstr Surg 2011;128:651-61.

4. Kim B, Roth C, Young L, et al. Anaplastic large cell lymphoma and breast implants: Results from a structured expert consultation process. Plast Recontr Surg 2011;128:629-39.

5. Lazzeri D, Agostini T, Bocci G, et al. ALK-1-negative anaplastic large cell lymphoma associated with breast implant: A new clinical entity. Clin Breast Cancer 2011;11:283-96.

6. Taylor KO, Webster HR, Prince HM. Anaplastic large cell lymphoma and breast implants: Five Australian cases. Plast Reconstr Surg 2012;129:610e-7e.

7. Anaplastic large cell lymphoma (ALCL) in women with breast implants: Preliminary FDA findings and analyses. <www.fda.gov/ medical devices> (Accessed June 2014).

8. De Jong D, Vasmel WL, de Boer JP, et al. Anaplastic large-cell lymphoma in women with breast implants. JAMA 2008;300:2030-5.

9. Spear SL, Rottman SJ, Glicksman C, Brown M, et al. Late seromas after breast implants: Theory and practice. Plast Reconstr Surg 2012;130:423-35.

10. Aladily TN, Medeiros LJ, Amin MB, et al. Anaplastic large cell lymphoma associated with breast implant: A report of 13 cases. Am J Surg Pathol 2012;36:1000-8.

11. Miranda RN, Aladilhy TN, Prince HM, et al. Breast implantassociated anaplastic large-cell lymphoma: Long-term follow-up of 60 patients. J Clin Oncology 2013:52:7911. 